\title{
Bovista (Lycoperdaceae): dois novos registros para o Brasil
}

\author{
Iuri Goulart Baseia ${ }^{1}$
}

Recebido em 02/04/2004. Aceito em 31/05/2005

RESUMO - (Bovista (Lycoperdaceae): dois novos registros para o Brasil). Duas espécies de Bovista ocorrentes em biomas de cerrado e caatinga são descritas: B. pila Berk. \& Curt.e B. plumbea Pers. São fornecidas imagens da ornamentação dos esporos em MEV e chave para identificação das espécies do gênero ocorrentes no Brasil.

Palavras-chave: Agaricales, Lycoperdaceae, gasteromicetos, taxonomia

ABSTRACT - (Bovista (Lycoperdaceae): two new records from Brazil). Two Bovista species occurring in cerrado and caatinga biomes are described: B. Pila Berk. \& Curt and B. plumbea Pers. SEM-photographs of spore ornamentation and a key for Brazilian species are provided.

Key words: Agaricales , Lycoperdaceae, gasteroid fungi, taxonomy

\section{Introdução}

O gênero Bovista foi criado por Persoon em 1794 e, de modo geral, assemelha-se a Calvatia e Lycoperdon, diferindo basicamente pelos basidiomas livres do substrato na maturidade, gleba desprovida de base estéril, capilícios formados em unidades discretas e ramificadas (Kreisel 1967; Miller \& Miller 1988) Estudos recentes de DNA causaram profundas alterações na sistemática deste grupo, que resultou na mudança de Lycoperdales para Agaricales (Hibbett et al. 1997). Dados moleculares ainda indicaram origem monofilética para o gênero Bovista e polifilética para Lycoperdon (Krüger et al. 2001). Segundo Agerer (2002), as características moleculares de rizomorfas confirmam a relação entre Lycoperdales e Agaricaceae.

Bovista possui aproximadamente 46 espécies amplamente distribuídas (Kirk et al. 2001). Destas, temos apenas três registros para o Brasil: Bovista africana Kreisel, B. bicolor Léveillé (= Langermannia wahlbergii (Fr.) Dring) e B. aestivalis (Homrich 1969; Rick 1961; Baseia 2005). Alguns representantes deste gênero são de interesse da pesquisa aplicada porque sintetizam metabólitos com potencial na produção de novos medicamentos (Jong \& Donovick 1989), como exemplo, tem-se Bovista plumbea Pers. que sintetiza proteínas antibióticas (Suay et al. 2000). O objetivo deste estudo é contribuir para o conhecimento taxonômico dos basidiomicetes no Brasil, principalmente os que ocorrem em áreas com vegetação nativa.

\section{Material e métodos}

As excursões para coletas foram realizadas mensalmente durante as estações chuvosas de 1999, totalizando três visitas para cada localidade, a saber: Estação Ecológica de Itirapina $\left(22^{\circ} 28^{\prime}-22^{\circ} 30^{\prime} \mathrm{S}\right.$ e $48^{\circ} 17^{\prime}-48^{\circ} 19^{\prime} \mathrm{W}$ ) e Reserva Biológica de Moji-Guaçu $\left(22^{\circ} 15^{\prime}-22^{\circ} 16^{\prime} \mathrm{S}\right.$ e $\left.47^{\circ} 08^{\prime}-47^{\circ} 12^{\prime} \mathrm{W}\right)$, ambas localizadas no Estado de São Paulo. Foram efetuadas ainda visitas mensais no período chuvoso de 2002, em áreas do semi-árido nordestino: Reserva Biológica de Serra Negra $\left(8^{\circ} 38^{\prime}-8^{\circ} 35^{\prime} \mathrm{S}\right.$ e $\left.38^{\circ} 02^{\prime}-38^{\circ} 04^{\prime} \mathrm{W}\right)$ e Reserva Biológica de Saltinho ( $8^{\circ} 43^{\prime}-8^{\circ} 45^{\prime}$ 'S e $35^{\circ} 10^{\prime}$ $\left.35^{\circ} 10^{\prime} \mathrm{W}\right)$, situadas no Estado de Pernambuco. Estas localidades foram escolhidas como parte de dois projetos mais amplos que visam o levantamento da diversidade dos gasteromicetos no cerrado e semiárido nordestino.

A análise do material seguiu as técnicas rotineiras empregadas em estudos taxonômicos de gasteromicetos (Miller \& Miller 1988). Foram feitas observações detalhadas dos esporos em microscópio eletrônico de varredura (MEV) Philips XL 20. Para os desenhos

\footnotetext{
1 Universidade Federal do Rio Grande do Norte, CB, Departamento de Botânica, Ecologia e Zoologia, Laboratório de Micologia, Campus Universitário, Lagoa Nova, CEP 59072-970, Natal, RN, Brasil (ibaseia@cb.ufrn.br)
} 
das microestruturas, utilizou-se câmara-clara acoplada ao microscópio; os basidiomas foram ilustrados com auxílio de câmara-clara acoplada ao estereomicroscópio. A terminologia micológica seguiu a nomenclatura proposta por Kirk et al. (2001). Para determinação da coloração foi utilizada a tabela de cores de Kornerup \& Wanscher (1978). Os espécimes estudados foram incorporados ao acervo dos Herbários SP e URM.

\section{Resultados}

Chave de identificação para as espécies de Bovista ocorrentes no Brasil

1. Basidiomas com 10-20 cm diâm.; capilícios homogeneamente distribuídos

B. bicolor

1. Basidiomas com 1-7 cm diâm., livres do substrato na maturidade; capilícios distribuídos em unidades discretas

2. Capilícios com poros; com ramificação irregular e extremidades truncadas

3. Esporos globosos (3,5-4 $\mu \mathrm{m}$ diâm.), pedicelo ausente

B. aestivalis

3. Esporos ovais a elípticos $(2,4-3 \times 4,2-5,4 \mu \mathrm{m})$, pedicelados

2. Capilícios sem poros; com ramificação dicotômica e extremidades pontiagudas

4. Exoperídio amarelo-claro; basidiosporos com apículo curto $(1-2 \mu \mathrm{m})$ 1. B. pila

4. Exoperídio marrom acinzentado; basidiosporos com apículo longo $(6-11 \mu \mathrm{m})$ 2. B. plumbea

1. Bovista pila Berk. \& Curt., Grevillea 2: 49, 1873. Bovista tabacina Sacc., Michelia 2: 565. 1880. Mycenastrum oregonense Ellis \& Everh., Journ. Mycol. 1: 89. 1885.

Bovista montana Morgan, Journ. Cininnati Soc. Nat. Hist. 14: 144. 1891 (Segundo Kreisel 1967)

Fig 1, 3 .

Basidiomas epígeos, globosos a subglobosos, 2-3cm. diâm. Exoperídio amarelo-claro (4A4, light yellow), 50-55 $\mu \mathrm{m}$ espessura, evanescente, superfície lisa; hifas pseudoparenquimatosas, hialinas, justapostas, irregulares a elípticas, 5-17×3-10 $\mu \mathrm{m}$. Endoperídio branco-amarelado (4A2, yellowish white), papiráceo; hifas 2-3 $\mu \mathrm{m}$ diâm. Gleba amarelo-acinzentada (4C3, greyish yellow), pulverulenta; capilícios castanho-claros, 4-8 um diâm., lisos, asseptados, ramificação dicotômica, extremidades pontiagudas, parede espessada, poros ausentes; basidiósporos globosos a subglobosos, 4-5,5 $\mu \mathrm{m}$ diâm., com apículo curto (1-2 $\mu \mathrm{m})$, ornamentação granulosa com grânulos isolados de tamanho e distribuição ligeiramente irregular.

Material examinado: BRASIL. São Paulo: Município de Moji-Guaçu, Reserva Biológica de MogiGuaçu, 14/I/1999, Baseia 806 (SP 307575), cerrado. Pernambuco: Reserva Biológica de Serra Negra, caatinga, 28/V/2002, Baseia 1076 (URM 77073).

Material adicional examinado: ESTADOS UNIDOS. Washington: det. W.B. Cooke \& V.G. Cooke (SP 60013); 6/IX/1947, W.B. Cooke \& V.G. Cooke (URM 12336).
Hábitat: Basidiomas solitários, crescendo em solo arenoso.

Distribuição geográfica: Estados Unidos e Canadá (Coker \& Couch 1928).
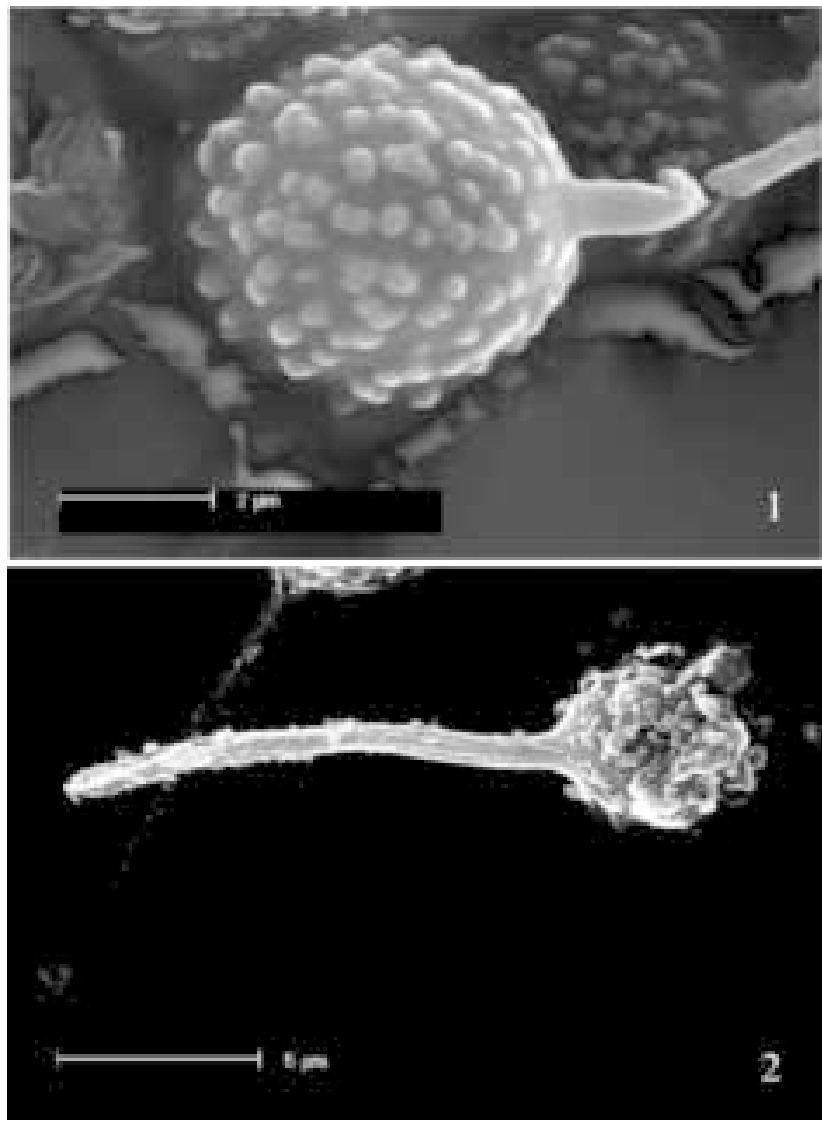

Figuras 1-2. Fotos MEV dos basidiosporos: 1. Bovista pila Berk. \& Curt. 2. Bovista plumbea Pers. 
Espécie pouco comum, ocorrendo exposta ao sol em solo arenoso de caatinga. Caracteriza-se basicamente pelos basidiomas amarelo-claros e basidiosporos globosos a subglobosos com apículo curto, características estas que coincidem com as do material adicional examinado e com a descrição feita por Coker \& Couch (1928). Este é o primeiro registro de B. pila para o Brasil.

2. Bovista plumbea Pers., Syn. Meth. Fung., 137. 1801.

Lycoperdon arrhizon Batsch, Elench. Fung. 2: 239. 1786.

Lycoperdon ardesiacum Bull., Hist. Champ. France, 146. 1791.

Bovista tunicata Fr., Syst. Mycol. 3(1): 25. 1829.

Bovista nuciformis Wallr., Fl. Crypt. Germ., 392. 1833.

Bovista ovalispora Cooke \& Massee, Grevillea 16: 46.1887.

Bovista brevicauda Velen., Ceské Houby, 832. 1922.

Bovista pallida Velen., Ceské Houby, 833. 1922.
Bovista purpurea C.G. Lloyd, Myc. Notes 6: 1201. 1923.

Bovista nigra Velen., Nov. Mycol. Noviss. 92. 1947.

Bovista sulphurea Velen., Nov. Mycol. Noviss., 92. 1947.

Bovista macrospora Perdeck, Blumea 6: 512. 1950. (Segundo Kreisel 1967)

Fig 2, 4.

Basidiomas epígeos, globosos a subglobosos, 2-2,5 cm alt. e 2-2,5 cm larg. Exoperídio marrom acinzentado (KW-5F3, greyish brown), 60-68 $\mu \mathrm{m}$ espessura, evanescente, superfície lisa; hifas pseudoparenquimatosas, castanhas, justapostas, circulares a elípticas, $12-30 \times 7-15 \mu \mathrm{m}$. Endoperídio cinza-escuro (KW-5E2, brownish grey), papiráceo; hifas 2,5-3,5 $\mu \mathrm{m}$ diâm. Gleba cinza-escura (KW-5F5, yellowish brown), pulverulenta; capilícios castanhoescuros, 3-7 $\mu \mathrm{m}$ diâm., lisos, asseptados, ramificação dicotômica, extremidades pontiagudas, parede espessada, poros ausentes; basidiosporos globosos a subglobosos, 4-5,5 $\mu \mathrm{m}$ diâm., apículo longo $(6-11 \mu \mathrm{m})$, ornamentação dos esporos irregular-escamosa.
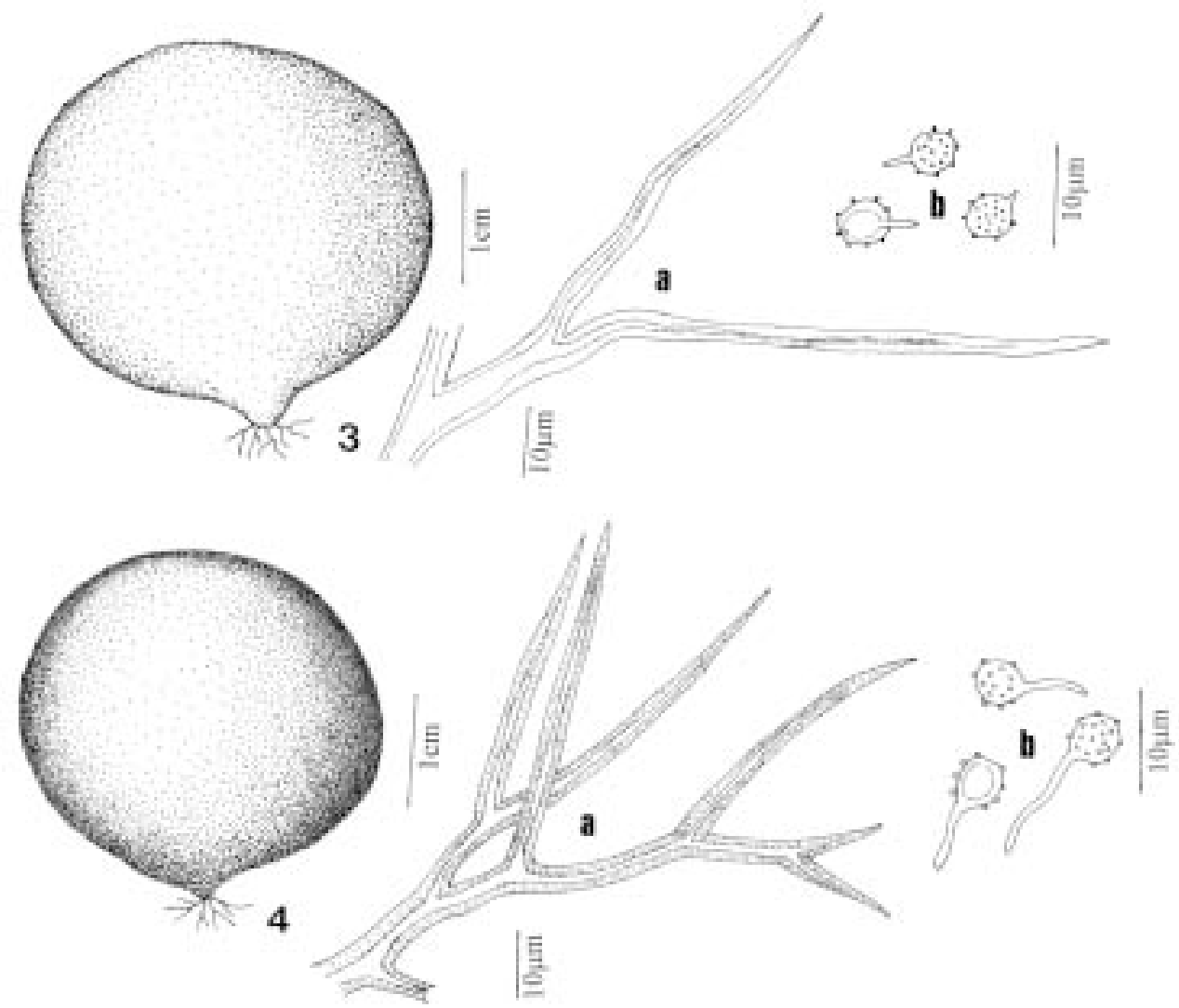

Figuras 3-4. Aspecto geral dos basidiomas: 3. Bovista pila Berk. \& Curt. a. Capilício. b. Basidiósporos. 4. Bovista plumbea Pers. a. Capilício. b. Basidiósporos. 
Material examinado: BRASIL. São Paulo: Município de Itirapina: Estação Ecológica de Itirapina, 24/II/1999, Baseia 854 (SP 307573); Pernambuco: Reserva Biológica de Saltinho, 16/IV/2002, Baseia 1056 (URM 77074), caatinga.

Material adicional examinado: ESTADOS UNIDOS. Columbia: 15/XI/1941, det. H.C. Aase (SP 60016); Arizona, 22/XI/1933, det. W.H. Long (URM 29934).

Hábitat: Basidiomas solitários crescendo em solo arenoso, próximos a Pouteria torta (Martius) Radlk.

Distribuição: Estados Unidos (Coker \& Couch 1928), Holanda (Perdeck 1950), Noruega (Eckblad 1955), África (Dring 1964), Alemanha (Kreisel 1967), Bélgica (Demoulin 1968; Moyersoen \& Demoulin 1996), Afeganistão (Lange 1973), Espanha (Calonge \& Demoulin 1975), Ilhas Canárias (Eckblad 1975), Itália (Monthoux \& Röllin 1976), Turquia (Watling \& Gregory 1977), França (Demoulin 1983), China (Liu 1984), México (Pardavé 1991; Ochoa et al. 2000).

Bovista plumbea é a espécie tipo do gênero e distingue-se de $B$. pila basicamente pelos basidiomas mais escuros e basidiósporos com pedicelo longo. Sob microscopia eletrônica de varredura a ornamentação dos esporos dos espécimes brasileiros difere da descrição fornecida por Monthoux (1982) por apresentar ornamentação bastante irregular, enquanto os esporos dos espécimes de Monthoux apresentaram ornamentação verrugosa. As características taxonômicas do material coincidiram com o material adicional examinado e com a descrição feita por Coker \& Couch (1928), Kreisel (1967) e Calonge \& Demoulin (1975). B. plumblea é pela primeira vez registrada para o Brasil.

\section{Agradecimentos}

Agradeço ao Conselho Nacional de Desenvolvimento Científico e Tecnológico (CNPq), pelo suporte financeiro; ao Departamento de Micologia,Universidade Federal de Pernambuco e à Seção de Micologia e Liquenologia, Instituto de Botânica, pelo suporte físico.

\section{Referências bibliográficas}

Agerer, R. 2002. Rhizomorph structures confirm the relationship between Lycoperdales and Agaricaceae (Hymenomycetes, Basidiomycota). Nova Hedwigia 75 (3-4): 367-385.

Baseia, I.G. 2005. Some notes on the genera Bovista and Lycoperdon (Lycoperdaceae) in Brazil. Mycotaxon 91(1): 81-86.
Calonge, F.D. \& Demoulin, V. 1975. Les Gastéromycètes d'Espanhe. Bulletin de la Société Mycologique de France 91(2): 247-292.

Coker, W.C. \& Couch, J.N. 1928. The Gasteromycetes of Eastern United States and Canada. Chapel Hill, Ed. Waverly Press.

Demoulin, V. 1968. Gastéromycètes de Belgique: Sclerodermatales, Tulostomatales, Lycoperdales. Bulletin du Jardin Botanique National de Belgique 38: 1-101.

Demoulin, V. 1983. Un site remarquable pour ses Gastéromycètes: Les grès rouges permiens du nord du Massif des Maures (var. France). Cryptogamie Mycologie 4: 9-18.

Dring, D. M. 1964. Gasteromycetes of West Tropical Africa. Mycological Papers 98: 1-60.

Eckblad, F.E. 1955. The Gasteromycetes of Norway. The Epigaean Genera. Nytt Magasin for Botanikk 4: 19-86.

Eckblad, F.E. 1975. Additions and corrections to the Gasteromycetes of the Canary Islands. Norwegian Journal of Botany 22: 243-248.

Hibbett, D.S.; Pine, E.M.; Langer, E.; Langer, G. \& Donoghue, M.J. 1997. Evolution of gilled mushrooms and puffballs inferred from ribossomal DNA sequences. Proceedings of the National Academy of Sciences of the United States of America 94: 12002-12006. POR EXTENSO

Homrich, M.H. 1969. Étude de quelques Gastéromicetes du Rio Grande do Sul. Revue de Mycologie 34(1): 3-16.

Jong, S. \& Donovick, R. 1989. Antitumor and Antiviral Substances from Fungi. Advances in Applied Microbiology 34: 183-262.

Kirk, P.M.; Cannon, P.F.; David, J.C. \& Stalpers, J.A. 2001. Ainsworth \& Bisby's Dictionary of the Fungi. $9^{\text {th }}$ Ed., Wallingford, CAB International, UK.

Kornerup, A. \& Wanscher, J.H. 1978. Methuen Handbook of Colour, $3^{\text {th }}$ ed. London, Eyre Methuen.

Kreisel, H. 1967. Taxonomisch-pflanzengeographische Monographie der Gattung Bovista. Beihefte zur Nova Hedwigia 25: 1-244.

Krüger, D.; Binder, M.; Fischer, M. \& Kreisel, H. 2001. The Lycoperdales. A molecular approach to the systematics of some gasteroid mushrooms. Mycologia 93(5): 947-957.

Lange, M. 1973. Some Gasteromycetes from Afghanistan. Botanisk Tidsskrift 50: 79-80.

Liu, B. 1984. The Gasteromycetes of China. Beihefte zur Nova Hedwigia 74:1-235.

Miller Junior, O.K. \& Miller, H.H. 1988. Gasteromycetes: Morphology and Developmental Features. Carter Lane Eureka, CA, Ed. Mad River, Eureka.

Monthoux, O. 1982. Micromorphologie des spores et capillitiums des Gastéromycètes des stations xériques de la region de Genève, etudiée au microscope électronique à balayage (SEM). Candollea 37(1): 63-99.

Monthoux, O. \& Röllin, O. 1976. La flore fongique des stations xériques de la region de Genève IV. Lycoperdaceae: genre Bovista Pers. Candollea 31: 247-256. 
Moyersoen, B. \& Demoulin, V. 1996. Les Gastéromycètes de Corse: Taxonomie, Écologie, Chorologie. Lejeunia 152: 1-129.

Ochoa, C.; Moreno, G.; Altés, A. \& Aguilar-Rodríguez, J.L. 2000. Gasteromycetes de Sierra Juárez (Baja California, México). Sociedad Micologica de Madrid 25: 157-165.

Pardavé, L.M. 1991. Gasteromicetos del Estado de Aquascalientes. Revista Mexicana de Micologia 7 : 71-78.

Perdeck, A.C. 1950. Revisión of the Lycoperdaceae of the Netherlands. Blumea 6(2): 480-516.
Persoon, C.H. 1794. Neuer Versuch einer systematischen Einteilung der Schwämme. Roemer's Neues Magazin für die Botanik 1: 63-128.

Rick, J. 1961. Basidiomycetes Eubasidii no Rio Grande do Sul. Brasília. Iheringia série Botânica 9: 451-480.

Suay, I.; Arenal, F.; Asensio, F.J.; Basilio, A.; Cabello, M.A.; Díez, M.T.; García, J.B.; Val, A.G.; Gorrochategui, J.; Hernández, P. \& Vicente, M.F. 2000. Screening of Basidiomycetes for antimicrobial activities. Antonie van Leeuwenhoek 78: 129-139.

Watling, R. \& Gregory, N.M. 1977. Larger fungi from Turkey, Iran and neighbouring countries. Karstenia 17: 59-72. 